\title{
вмJ Global Health Cost-effectiveness of scaling up of hepatitis $C$ screening and treatment: a modelling study in South Korea
}

\author{
Jungyeon Kim, ${ }^{\oplus 1}$ Markus Haacker, ${ }^{1,2}$ Salmaan Keshavjee, ${ }^{3}$ Rifat Atun ${ }^{\odot 1,4}$
}

To cite: Kim J, Haacker M, Keshavjee S, et al. Costeffectiveness of scaling up of hepatitis $\mathrm{C}$ screening and treatment: a modelling study in South Korea. BMJ Global Health 2019;4:e001441. doi:10.1136/ bmjgh-2019-001441

Handling editor Seye Abimbola

Received 25 January 2019

Revised 22 April 2019

Accepted 27 April 2019

Check for updates

(C) Author(s) (or their employer(s)) 2019. Re-use permitted under CC BY-NC. No commercial re-use. See rights and permissions. Published by BMJ.

${ }^{1}$ Department of Global Health and Population, Harvard TH Chan School of Public Health, Harvard University, Boston, Massachusetts, USA

${ }^{2}$ Centre for Global Health Economics, University College London, London, UK

${ }^{3}$ Center for Global Health Delivery - Dubai, Harvard Medical School, Harvard University, Boston, Massachusetts, USA ${ }^{4}$ Department of Global Health and Social Medicine, Harvard Medical School, Harvard University, Boston, Massachusetts, USA

Correspondence to Dr Rifat Atun; ratun@hsph.harvard.edu

\section{ABSTRACT}

Background The prices and the coverage of effective direct-acting antivirals (DAAs) to treat hepatitis $C$ vary across countries. South Korea expanded DAAs coverage through national health insurance. This study aims to analyse the cost-effectiveness of scale-up of hepatitis $C$ screening and treatment with DAAs in South Korea, a highincome country.

Methods This study uses a compartmental age-sex structured model of progression of hepatitis $\mathrm{C}$ to analyse effects of different policy choices for the scale up of screening and treatment with DAAs on hepatitis $C$ disease burden and costs from 2017 to 2050. Policy scenarios considered in our study are (1) no treatment, (2) status quo, (3) screening population aged over 60 years, (4) screening population over 40 years and (5) screening population aged over 20 years.

Results The continuation of current policy with the expansion of DAAs coverage is estimated to reduce the prevalence of hepatitis $\mathrm{C}$ antibody from $0.6 \%$ in 2015 to $0.25 \%$ in 2050 of the adult population. Status quo policy, screening from age 60 , screening from age 40 and screening from age 20 are cost-effective in terms of averted infection at estimated incremental cost-effective ratio of US\$101 208, US\$111770, US\$107 909 and US\$229604.

Conclusions The expansion of DAAs coverage by the national health insurance is highly effective in alleviating hepatitis $\mathrm{C}$ disease burden. The scale-up of screening and treatment with DAAs for targeted adult population with high prevalence of hepatitis $C$ is cost-effective. This study provides a case for policy-makers to invest in rapid expansion of hepatitis $C$ comprehensive screening and treatment with DAAs.

\section{INTRODUCTION}

Direct-acting antivirals (DAAs) have substantially improved effectiveness of treating viral hepatitis $\mathrm{C}$ and improved cure rates higher than $90 \%$, as a result of improved sustained virological response (SVR) rate, shorter length of therapy (8 weeks) and minimised side effects. ${ }^{1}$ However, DAAs are costly and largely unavailable in low/middle-income countries (LMICs).$^{1-3}$ There have been global efforts to expand access to DAAs by including

\section{Key questions}

What is already known?

- The introduction of direct-acting antivirals (DAAs) greatly improved the effectiveness of treatment for hepatitis $\mathrm{C}$, and therefore there are global efforts to expand access to expensive DAAs in low/middle-income countries (LMICs). However, DAAs are costly. While the coverage of treatment with DAAs varies considerably in high-income countries, coverage in LMIC is very low.

\section{What are the new findings?}

- In addition to the construction of compartmental age-sex model along hepatitis $\mathrm{C}$ disease progression, the results of this study provide new evidence that the expansion of DAAs coverage by national health insurance and scale-up of hepatitis $\mathrm{C}$ screening and treatment with DAAs are cost-effective.

- This study provides a comprehensive assessment of economic and health impacts from scaling up hepatitis $\mathrm{C}$ screening and treatment with DAAs in one high-income country.

\section{What do the new findings imply?}

- Scaling up hepatitis C screening and treatment with DAAs to adult population is cost-effective as it averts additional hepatitis $C$ infections and death from hepatitis $\mathrm{C}$, but saves care and treatment costs of cirrhosis and other diseases caused by untreated hepatitis C.

- Findings provide a case for policy-makers in high-income countries to invest in expansion of hepatitis C screening and treatment with DAAs through health insurance coverage.

DAAs in country lists of essential drugs and making them available at steeply discounted prices through voluntary license agreements across LMICs, such as Egypt ${ }^{4}$ and South Africa, ${ }^{5}$ to eliminate hepatitis $\mathrm{C}$.

In high-income countries (HICs), price of DAAs varies considerably as does coverage ${ }^{6-8}$ but there are few published studies on coverage of DAAs in HIC setting and in LMICs and the cost-effectiveness of scaling up screening and treatment. ${ }^{9} 10$ 


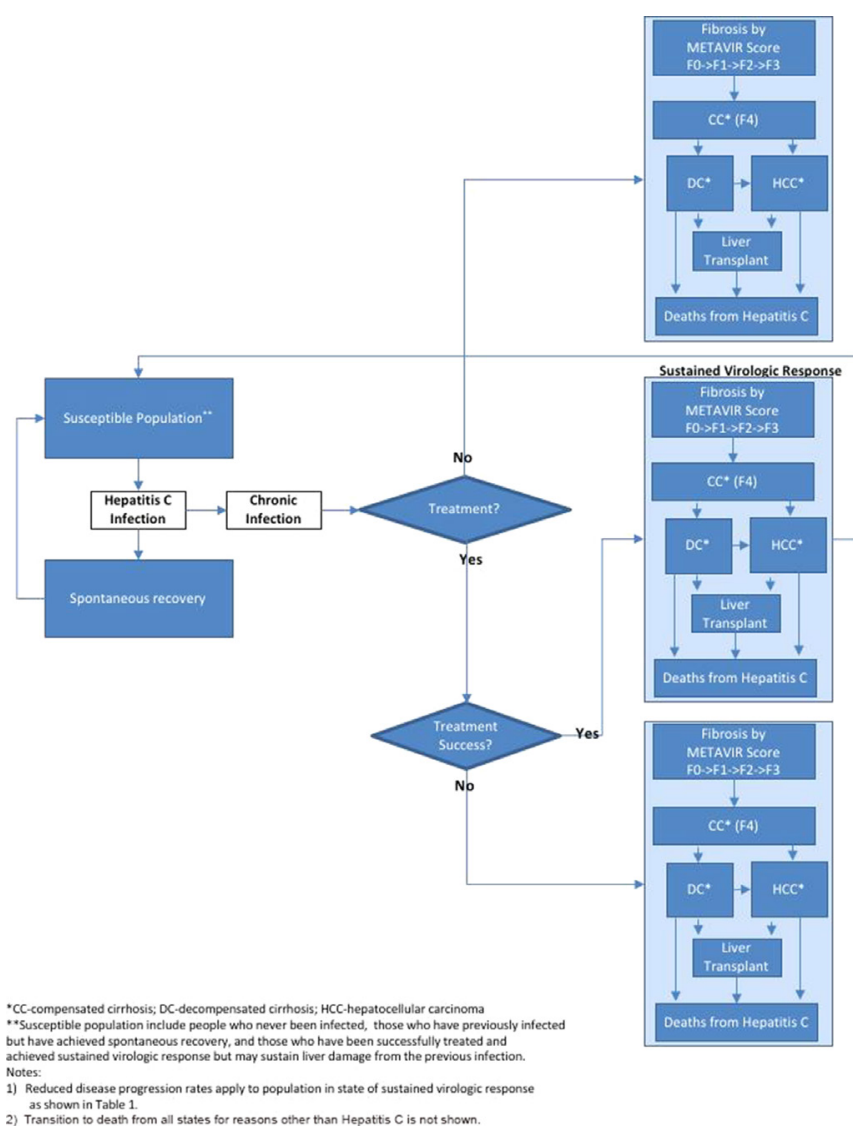

Figure 1 Hepatitis C model structure.

South Korea (hereafter Korea) is one country that has made DAAs (sofosbuvir and ledipasvir/sofosbuvir in 2016, followed by daclatasvir in 2015) available through Korean National Health Insurance Scheme (NHIS) (online supplementary table A1). ${ }^{1-3} 11$ The estimated prevalence rate of hepatitis C antibody in Korea is $0.7 \%$, which is lower than the estimated global rate $(1 \%) .{ }^{12} 13$

In Korea, approximately $70 \%-80 \%$ of people infected with hepatitis $\mathrm{C}$ virus (HCV) become chronically infected and $30 \%-40 \%$ of those who are chronically infected progress to liver cirrhosis or liver cancer. ${ }^{14}$ However, only 1 out of 10 Koreans had screening for hepatitis C and $35 \%$ of those who knew that they had hepatitis $\mathrm{C}$ were treated due to the poor knowledge of hepatitis $\mathrm{C}$ according to the survey conducted by Korean Association for the Study of Liver in 2016. ${ }^{14}$

Korean citizens are eligible for a biannual general health screening, paid for by the NHIS, with $76 \%$ coverage of the eligible population. ${ }^{15}$ The insurance scheme also funds 'life-turning-point' health examination at ages 40 and 66, cancer screening and health screenings for infants. These schemes provide an opportunity to screen a large proportion of the population for hepatitis $\mathrm{C}$ for a small additional cost.

This paper uses a compartmental age-sex structured model of progression of hepatitis $\mathrm{C}$ to examine the costs and effects of different policy choices relating to scale-up of screening and treatment with DAAs for hepatitis $\mathrm{C}$ in Korea. The study aims to fill a knowledge gap on cost-effectiveness of scaling up screening and treatment to eliminate hepatitis $\mathrm{C}$ in HICs. ${ }^{78}$

\section{METHODS \\ Model description}

Figure 1 presents our compartmental model structure used in the study following the natural history of HCV. The population was stratified by age and sex and divided into two categories: category A with access to general health screening and category $\mathrm{B}$ without access to general health screening-allowing for some transition between the groups. This distinction is necessary because regular health screenings are one mode of detection of hepatitis $\mathrm{C}$, and some of the policies studied envisage including testing for hepatitis $\mathrm{C}$ as part of the general health screening. The national health insurance programme in Korea offers biannual general health screening based on the birth year (even/odd) to heads of households and members of households aged 40 or older, non-office employees, office employees and employee dependents aged 40 or older. ${ }^{15}$ General health screening rate of eligible population was $76 \%$ in $2015,{ }^{15}$ and we assume an annual transition rate of $5 \%$ from category A to B. The transition rate from category $\mathrm{B}$ to $\mathrm{A}$ is set so that the distribution of the population between types remains constant. For example, if a stable $76 \%$ of the population is assigned to type $\mathrm{A}$, a transition rate of $5 \%$ from type $\mathrm{A}$ to type B implies a transition from type B to type A of $15.8 \%$. Once people are chronically infected with HCV, they follow typical progression of HCV infection, as described by stages of liver disease which are Meta-analysis of Histological Data in Viral Hepatitis (METAVIR) scores F0 to F3, compensated cirrhosis (METAVIR score F4), decompensated cirrhosis and hepatocellular carcinoma. ${ }^{16} 17$ Following treatment with DAAs, patients progress either to SVR (ie, they are no longer RNA positive but remain indexed by liver damage sustained, with reduced disease progression) or treatment failure (disease progression same as for untreated population) (table 1). For the susceptible population, those who are not RNA positive, incidence is proportional to the number of people infected, and largely homogeneous across the population, differing only between adults and children, and for adults by sex. Susceptible population include people who never been infected, those who have previously infected but have achieved spontaneous recovery and those who have been successfully treated and achieved sustained virological response but may sustain liver damage from the previous infection.

The epidemiological model is embedded in demographic estimates and projections on the population size and overall mortality by age and sex from World Population Prospects $2017 .^{18}$

\section{Parameterisation}

The model was parameterised using global burden of disease data for $2015,{ }^{19}$ and Korean data from multiple 
Table 1 Key model parameters used for the projection analysis

\section{Value}

\section{Source}

\begin{tabular}{llll}
\hline Initial population (2015) & & & \\
\hline Hepatitis C prevalence & Male & Female & KHNAES $^{20}$ \\
\hline Antibody & $0.6 \%$ & $0.7 \%$ & 12 \\
\hline HCV RNA & $0.3 \%$ & $0.4 \%$ & HIRA $^{25}$ \\
\hline No of people on DAAs treatment & & & \\
2015 & $26 \mathrm{~K}$ & $31 \mathrm{~K}$ & \\
2016 & $23 \mathrm{~K}$ & & \\
\hline
\end{tabular}

\section{Fixed parameters}

$\begin{array}{llll}\text { Mortality from hepatitis C } & \text { HCV RNA } & \text { HCV antibody } & \\ \text { Up to CC } & 0 & 0 & 1923 \\ \text { HCC } & 0.20 & 0.20 & 1923 \\ \text { DCC } & 0.15 & 0.15 & 19212324 \\ \text { Liver transplant } & 0.10 & 0.10 & \end{array}$

Mortality from other causes $\quad$ Sex-specific and age-specific estimates and projections based on World ${ }^{18}$ Population Prospects 2017

\begin{tabular}{lll} 
Incidence of hepatitis C & $\begin{array}{l}\text { Constant 'thrust of infection' parameters, implying } \\
0.06 \% \text { in } 2015 .\end{array}$ & 0.45 \\
\hline Spontaneous clearance & 0.45 & Female \\
& & Normal/SVR \\
\hline Hepatitis C disease progression & $\begin{array}{l}\text { Male } \\
\text { Normal/SVR }\end{array}$ & $0.061 / 0.000$ \\
\hline F0 to F1 & $0.181 / 0.000$ & $0.044 / 0.000$ \\
F0 to F2 & $0.132 / 0.000$ & $0.063 / 0.000$ \\
F2 to F3 & $0.186 / 0.000$ & $0.046 / 0.014$ \\
F3 to CC & $0.128 / 0.038$ & $0.002 / 0.000$ \\
F3 to HCC & $0.004 / 0.001$ & $0.029 / 0.009$ \\
CC to HCC & $0.052 / 0.016$ & $0.022 / 0.010$
\end{tabular}

\begin{tabular}{|c|c|c|c|c|c|}
\hline \multirow[t]{2}{*}{ Sustained virological response rates } & \multicolumn{2}{|l|}{ Male } & \multicolumn{2}{|l|}{ Female } & \multirow[t]{2}{*}{ WHO 39} \\
\hline & 0.95 & & 0.95 & & \\
\hline \multirow[t]{2}{*}{ General health screening rate } & \multicolumn{2}{|l|}{ Male } & \multicolumn{2}{|l|}{ Female } & $\mathrm{NHIS}^{15}$ \\
\hline & A & B & A & B & \\
\hline \multicolumn{6}{|l|}{ Age } \\
\hline Under 20 years & 0 & 1.00 & 0 & 1.00 & \\
\hline 20-29 years & 0.40 & 0.60 & 0.40 & 0.60 & \\
\hline 30-39 years & 0.75 & 0.25 & 0.50 & 0.50 & \\
\hline 40 years and over & 0.75 & 0.25 & 0.75 & 0.25 & \\
\hline $\begin{array}{l}\text { Transition rate between category } \mathrm{A} \\
\text { and } \mathrm{B}\end{array}$ & \multicolumn{4}{|c|}{$\begin{array}{l}\text { From age } 40,5 \% \text { from } A \text { to } B \text {, } \\
15.8 \% \text { from } B \text { to } A\end{array}$} & $\begin{array}{l}\text { Assumption (online } \\
\text { supplementary appendix 1) }\end{array}$ \\
\hline \multicolumn{6}{|l|}{ Costs parameters } \\
\hline \multicolumn{6}{|l|}{ Hepatitis C screening } \\
\hline Antibody test & \multicolumn{2}{|c|}{ US $\$ 20$} & \multicolumn{2}{|l|}{ Test } & 25 \\
\hline RNA test & \multicolumn{2}{|c|}{ US\$150 } & \multicolumn{2}{|l|}{ Test } & 25 \\
\hline \multicolumn{6}{|l|}{ Treatment costs } \\
\hline Chronic hepatitis C & \multicolumn{2}{|c|}{ US\$10 000} & \multicolumn{2}{|l|}{ Patient } & 26 \\
\hline $\mathrm{CC}$ & \multicolumn{2}{|c|}{ US\$2064 } & \multicolumn{2}{|l|}{ Patient } & 32 \\
\hline DC & \multicolumn{2}{|c|}{ US\$6146 } & \multicolumn{2}{|l|}{ Patient } & 32 \\
\hline
\end{tabular}

Derived from national prevalence estimates

Set to match observed prevalence data (antibodies and RNA)

Average across ages Age-specific progression as used by Razavi et al, ${ }^{27}$ adjusted by common factor across ages to match prevalence and mortality rate for Korea

Continued 
Table 1 Continued

\begin{tabular}{llll}
\hline & Value & & Source \\
\hline HCC & US $\$ 8000$ & Year & 22 \\
Liver transplant & US $\$ 35000$ & Case & 33 \\
Postliver transplant & US $\$ 5000$ & Year & 33 \\
\hline
\end{tabular}

CC, compensated cirrhosis; DAAs, direct-acting antivirals; DC, decompensated cirrhosis; HCC, hepatocellular carcinoma; HCV, hepatitis C virus; HIRA, Health Insurance Review and Assessment Service; KHNAES, Korea National Health and Nutrition Examination Survey; NHIS, National Health Insurance Scheme; SVR, sustained virological response.

sources, including Korea National Health and Nutrition Examination Survey, Health Insurance Review and Assessment Service (HIRA), NHIS, Statistics Korea, Korean Organ Transplantation Registry and published articles on prevalence of hepatitis $\mathrm{C},{ }^{20}$ mortality related to hepatitis $\mathrm{C},{ }^{21-24}$ treatment $^{2124-26}$ and assumptions on disease progression from a substantial cross-country modelling study differentiated by stage of disease, sex and age (table 1$){ }^{27}$

\section{Analysis}

We simulated the effects of five different policy interventions on the hepatitis $\mathrm{C}$ prevalence and mortality rate in each year from 2017 to 2050: (1) no treatment, (2) status quo, that is, demand-driven screening and treatment when people have symptoms and seek healthcare services, prioritising the screening for population with high prevalence according to WHO's recommendation, ${ }^{28}$ (3) population aged over 60 years and treating people who are chronically infected with HCV, (4) screening population aged over 40 and treating people who are chronically infected with HCV and (5) screening population aged over 20 years and treating people who are chronically infected with HCV. We assumed that the eligible populations could be screened and treated over 2 years (2017 and 2018).

For each policy option, we analysed for the period 2017-2050 the financial consequences of expanding screening and treatment with DAAs by projecting the yearly costs of treatment with DAAs and the costs of treatment for cirrhosis or hepatic cancer to capture savings, which can be attributed to treatment with DAAs. All costs are reported in 2016 prices, using a year-average exchange rate of KRW 1160 per US dollar for $2016^{29}$ to convert costs in Korean won to those in US dollars and applying a discount rate of $3 \% .^{30}$

We analysed the cost-effectiveness of the five policy interventions considered in our study to identify the optimal hepatitis $\mathrm{C}$ policy intervention related to the treatment with DAAs. For the cost-effective analysis, we included DAAs that were approved and listed in the national health insurance benefit packages in Korea, namely: Sunvepra (Bristol-Myers), Daclinza (Bristol-Myers), Harvoni (Gilead) and Sovaldi (Gilead) (online supplementary appendix table A1).

Table 1 summarises cost estimates used for our simulation across hepatitis $\mathrm{C}$ disease stages. The principal data used for estimated hepatitis $\mathrm{C}$ treatment costs with DAAs and the screening costs for hepatitis $\mathrm{C}$ were the medical claims data provided by HIRA from 2012 to $2016,{ }^{25}$ and the list of drug prices provided by the Korean Ministry of Health and Welfare based on the assumption that people with chronic hepatitis $\mathrm{C}$ were treated only with DAAs from 2016 (table 1, online supplementary appendix A1, appendix table A1). ${ }^{31}$ The treatment costs, depending on hepatitis $\mathrm{C}$ disease progression stages, were estimated from the published literature or from the data obtained from the website of tertiary teaching hospitals (table 1)..$^{32} 33$

Because of the long duration of a hepatitis C infection, we provide an alternative perspective on the consequences of new hepatitis $\mathrm{C}$ infections under different scenarios, taking a life-cycle perspective on the consequences of a cohort of size 100, representative for the population of ages 20-50, which contracts hepatitis $\mathrm{C}$ in 2016 (online supplementary appendix A3). Additional costs and mortality are then calculated as the difference between the respective outcomes for this scenario, including the 100 additional infections, and the underlying scenario not including them. To receive a better perspective on the life-cycle effects of the new infections, the time horizon for this analysis is set to 2080 rather than 2050 as elsewhere in this paper (online supplementary appendix A3). The analysis of our model was implemented and conducted in Microsoft Excel.

\section{Patient and public involvement}

Patients were not involved.

\section{RESULTS}

Figure 2 shows estimated effect of different policy scenarios on the number of people chronically infected with $\mathrm{HCV}$, new infections and deaths from hepatitis $\mathrm{C}$. The number of chronically infected people with hepatitis $\mathrm{C}$ and death from hepatitis $\mathrm{C}$ are projected to decrease from 2017 to 2050 in all scenarios considered in our study (figure 2). The prevalence rate of chronic hepatitis $\mathrm{C}$ under the status quo policy with the coverage expansion of the treatment with DAAs is projected to decrease from 0.3 in 2015 to 0.02 in 2050 (figure 2A). The number of people chronically infected with hepatitis C declines most rapidly in 2017-2019 with the introduction of comprehensive screening for people aged 20 years or more, followed by screening for people aged 40 years and then screening people aged 60 years or more. 


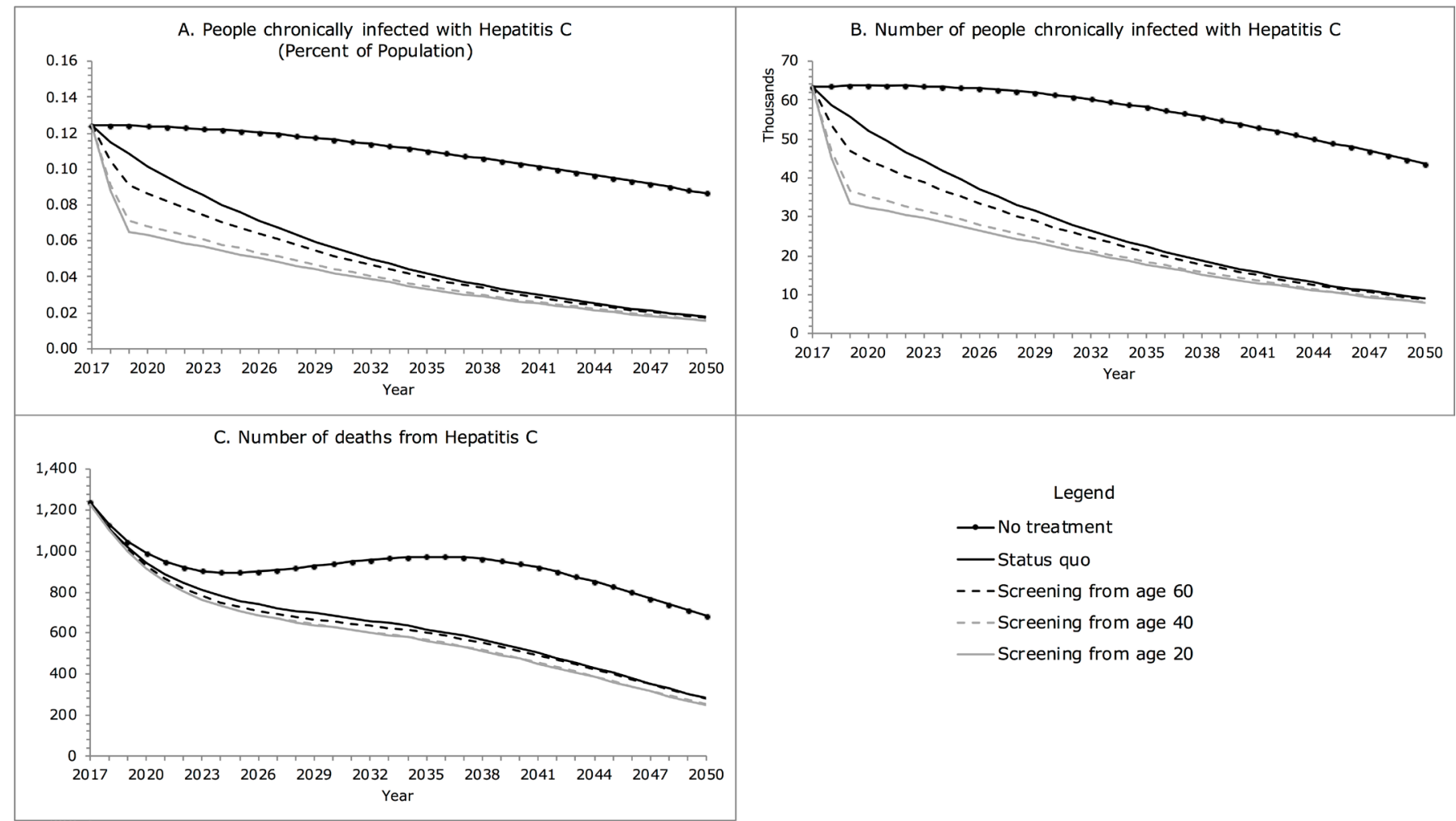

Figure 2 Epidemiological figures of hepatitis $C$ under different policy scenarios.

In 2030, compared with status quo policy, comprehensive screening reduces the number of people chronically infected by $8 \%$ if people over 60 years or more were screened, by $21 \%$ if people aged 40 years or more were screened and by $25 \%$ if all adults aged 20 years or more were screened (figure 2B).

The number of people chronically infected with hepatitis $\mathrm{C}$ declines more rapidly in the population with access to national health screening (category A) provided by the national health insurance corporation than those without (category B). In 2030, compared with the status quo policy, comprehensive screening reduces the number of people chronically infected with access to national health screening (category A) and those without (category B) by $10 \%$ and $6 \%$, respectively, if people over 60 years or more were screened; by $26 \%$ and $15 \%$, respectively, if people

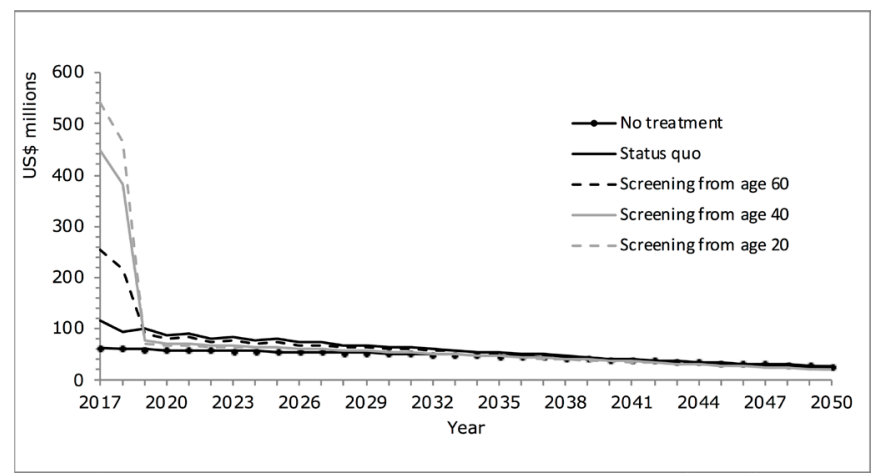

Figure 3 Projected costs under different policy scenarios by year. aged 40 years or more were screened; and by $31 \%$ and $17 \%$, respectively, if all adults aged 20 years or more were screened (online suppplementary appendix table A2.1).

Between 2017 and 2030, deaths from hepatitis C decline sharply with all policy scenarios except no treatment scenario by $44 \%$ with opportunistic screening under status quo policy, by $47 \%$ with screening for adults aged 60 years or more, by $49 \%$ with screening for those aged 40 years or more and by $49 \%$ with screening for those aged 20 years or more (figure $2 \mathrm{C}$ ). Compared with the status quo policy, comprehensive screening policies reduce deaths from hepatitis $\mathrm{C}$ more for people with access to national health screening (category A) than for those without (category B) (online supplementary appendix table A2.1). In 2030, the deaths from hepatitis $\mathrm{C}$ for category A and category $\mathrm{B}$ are projected to decline by $4 \%$ and $3 \%$, respectively, if people aged 60 years or more were screened; by $9 \%$ and $6 \%$, respectively, if people aged 40 years or more were screened; and by $9 \%$ and $6 \%$, respectively, if people aged 20 years or more were screened (online supplementary appendix table A.2.1).

Figure 3 presents projected healthcare expenditures (public and private) on hepatitis $\mathrm{C}$ screening and treatment for the period 2017-2050 with different hepatitis C policy scenarios, which amount to US\$2584 millions under the current status quo policy, US\$3070 millions with screening introduced for adults aged 20 years or more, US\$2933 millions with screening for those aged 40 years or more and and US $\$ 2740$ millions with screening for those aged 60 years or more. 
Table 2 provides a summary of costs and health impacts in terms of hepatitis $\mathrm{C}$ infections averted or deaths averted and incremental cost-effective ratio (ICER) for different policy scenarios for the period 2017-2050. ICER is expected to reduce over time from US\$1 074867 in 2018 to US $\$ 111770$ in 2050 in terms of infection averted and from US\$19 277053 in 2018 to US $\$ 433822$ in 2050 in terms of death averted if people aged 60 or more were screened, from US\$1 260665 in 2018 to US\$107 909 in 2050 in terms of infection averted and from US $\$ 77654$ 439 in 2018 to US $\$ 473325$ in 2050 in terms of death averted if people aged 40 or more were screened. In 2030, ICER for screening from age 60 in terms of infection averted is estimated at US\$141311 compared with status quo and that for screening from age 40 at US $\$ 155$ 163 compared with screening from age 60 (table 2). Screening from age 20 was dominated for not increasing the number of death averted with additional costs in 2018 and in 2020 (table 2). In 2050, ICERs in terms of infection averted for status quo screening, screening from age 60 and screening from 40 were similar at US $\$ 101208$, US $\$ 111770$ and US $\$ 107909$, respectively, but that for screening from 20 was estimated to double at US\$229 604 (table 2).

Table 3 illustrates the cost-effectiveness of treatment for specific 10-year age brackets around the status quo scenario. In this scenario, there is a strong probability that an individual would eventually be diagnosed through the regular health screening. This means that most of the individuals placed on treatment additionally in 2017 in the experiment summarised in table 3 would otherwise progress to treatment later on, rather than never receiving treatment. This is reflected in the 'HepC treatment' component under savings, showing the discounted value of the obviated later treatment costs. Savings in the costs of treatment for cirrhosis reflect that liver disease owing to hepatitis $\mathrm{C}$ tends to be more advanced among individuals treated at older ages, but also factors like differences in disease progression by age and sex and underlying mortality. The effectiveness of placing additional persons on treatment declines with age in terms of infections averted because of longer period to treatment under the counterfactual, and increases in terms of deaths averted because it tends to be more effective to prevent progression to the most advanced stages of disease until old age when mortality for other causes increases steeply (table 3 ).

Overall, earlier treatment is cost-saving for male adults from the age group 20-29 to 50-59 in that the costs of earlier treatment are more than offset by the financial gains from reduced progression to advanced stages of liver disease (table 3). For female adults, earlier treatment is not cost-saving and less cost-effective than for males, reflecting slower disease progression. For this reason and lower underlying mortality among women, the best cost-effectiveness is attained for older ages- the age groups $60-69$ or 50-59, while for men the cost-effectiveness is best for the $40-49$ age group (table 3 ).
Online supplementary appendix figures A1 and A2 show a life-cycle perspective, focusing on a population (100 individuals, representative of the population at ages 20-50) who became infected with hepatitis C in 2016. Online supplementary figure A1 shows projections on the consequences of these additional infections in terms of elevated mortality caused by hepatitis C. The status quo policy reduces mortality caused by hepatitis $\mathrm{C}$ by about three-quarters (online supplementary appendix figure A1.A). Screening from age 40 policy reduces mortality caused by hepatitis $\mathrm{C}$ by another $25 \%$ relative to status quo policy, but this corresponds to an additional gain of only $4 \%$ relative to the level of mortality to the survival curve because this is counted against a diminished denominator (online supplementary appendix figure A1.B).

The magnitude and profile of costs associated with these outcomes differ considerably across policy scenarios under this life-cycle perspective similar to the policy analysis above. Without treatment, the costs of treatment for cirrhosis or liver cancer caused by hepatitis $\mathrm{C}$ rose to an average of about US\$265 annually at 2016 constant prices after about 30 years, and added up to an expected US\$3306 per case, discounted at a rate of $3 \%$ (online supplementary appendix figure A2.A). Under the status quo scenario, the costs caused per new infection were higher, at US $\$ 5612$ overall (online supplementary appendix figure A2.B). Annual costs peak right away, as some individuals who become infected are diagnosed early and receive treatment, while the costs of treatment of the consequences of hepatitis $\mathrm{C}$ (cirrhosis and liver cancer) also build up over 30 years but are reduced by over $60 \%$ overall (online supplementary figure A2.B). Under the screening intervention for people over the age of 40 , total costs estimated at US\$5554 are lower than those under the status quo policy scenario (online supplementary appendix figure A2.C).

\section{DISCUSSION}

Korea expanded access to hepatitis $\mathrm{C}$ treatment with DAAs covered by national insurance in 2015 and $2016 .{ }^{2526}$ Model findings suggest the expansion will help reduce the prevalence of hepatitis $\mathrm{C}$ chronic infection from $0.3 \%$ in 2015 to $0.1 \%$ in 2050 (figure 2).

Our estimates suggest that in 2016 approximately half $(46 \%)$ of Koreans chronically infected with HCV and $16 \%$ of Koreans carrying HCV antibodies received the treatment with DAAs. This estimate is consistent result of a prior study that estimated $17 \%$ of Korean people carrying HCV antibodies had access to treatment in $2015 .{ }^{34}$

Our projections also suggest that continuation of the current policy will help reduce the prevalence of hepatitis $\mathrm{C}$ antibody from $0.6 \%$ of the adult population to $0.25 \%$ by 2050 . This result implies that the rapid expansion of DAAs coverage with existing national health screening 
Table 2 Cost and health impacts of different policy options 2017-2050

\section{Accumulated costs and impacts until}

\begin{tabular}{|c|c|c|c|c|c|}
\hline & \\
\hline & 2018 & 2020 & 2030 & 2040 & 2050 \\
\hline \multicolumn{6}{|c|}{ Total infections averted } \\
\hline Status quo & 203 & 689 & 5148 & 10019 & 13690 \\
\hline Screening from 60 & 434 & 1259 & 6475 & 11516 & 15231 \\
\hline Screening from 40 & 707 & 1936 & 8197 & 13561 & 17374 \\
\hline Screening from 20 & 784 & 2129 & 8685 & 14146 & 17992 \\
\hline \multicolumn{6}{|c|}{ Total hepatitis C-related deaths averted } \\
\hline Status quo & 21 & 84 & 1194 & 3168 & 4913 \\
\hline Screening from 60 & 33 & 128 & 1456 & 3536 & 5310 \\
\hline Screening from 40 & 38 & 144 & 1616 & 3888 & 5798 \\
\hline Screening from 20 & 38 & 144 & 1623 & 3908 & 5835 \\
\hline \multicolumn{6}{|c|}{ Total costs (US\$ millions) } \\
\hline Status quo & 202 & 373 & 954 & 1252 & 1386 \\
\hline Screening from 60 & 451 & 603 & 1141 & 1427 & 1558 \\
\hline Screening from 40 & 795 & 926 & 1409 & 1670 & 1789 \\
\hline Screening from 20 & 965 & 1091 & 1558 & 1815 & 1931 \\
\hline
\end{tabular}

\section{Average cost per infection averted (US\$)}

\begin{tabular}{|c|c|c|c|c|c|}
\hline Status quo & 998170 & 540669 & 185297 & 124948 & 101208 \\
\hline Screening from 60 & 1039029 & 478851 & 176287 & 123948 & 102276 \\
\hline Screening from 40 & 1124565 & 478359 & 171848 & 123177 & 102971 \\
\hline Screening from 20 & 1230596 & 512246 & 179437 & 128302 & 107320 \\
\hline \multicolumn{6}{|c|}{ Average cost per deaths averted (US\$) } \\
\hline Status quo & 9867435 & 4456291 & 799119 & 395182 & 282029 \\
\hline Screening from 60 & 13498659 & 4720165 & 783710 & 403650 & 293380 \\
\hline Screening from 40 & 21007361 & 6420448 & 871637 & 429658 & 308537 \\
\hline Screening from 20 & 25439608 & 7536489 & 960442 & 464426 & 330929 \\
\hline
\end{tabular}

\section{Incremental cost-effectiveness ratio (ICER)}

\section{Incremental infection averted}

\begin{tabular}{lllrrr} 
Status quo & 203 & 689 & 5148 & 10019 & 13690 \\
\hline Screening from 60 & 231 & 570 & 1326 & 1497 & 1541 \\
\hline Screening from 40 & 273 & 677 & 1723 & 2046 & 2143 \\
Screening from 20 & 78 & 193 & 488 & 585 & 618 \\
\hline
\end{tabular}

\section{Incremental deaths averted}

\begin{tabular}{|c|c|c|c|c|c|}
\hline Status quo & 21 & 84 & 1194 & 3168 & 4913 \\
\hline Screening from 60 & 13 & 44 & 263 & 368 & 397 \\
\hline Screening from 40 & 4 & 16 & 160 & 352 & 489 \\
\hline Screening from 20 & 0 & 0 & 6 & 20 & 36 \\
\hline \multicolumn{6}{|c|}{ Incremental costs (US\$ millions) } \\
\hline Status quo & 202 & 373 & 954 & 1252 & 1386 \\
\hline Screening from 60 & 248 & 230 & 187 & 176 & 172 \\
\hline Screening from 40 & 344 & 323 & 267 & 243 & 231 \\
\hline Screening from 20 & 170 & 164 & 150 & 144 & 142 \\
\hline
\end{tabular}

Incremental cost-effectiveness ratio (infection averted)

$\begin{array}{llllll}\text { Status quo } & 998170 & 540669 & 185297 & 124948 & 101208 \\ \text { Screening from 60 } & 1074867 & 404093 & 141311 & 117260 & 111770\end{array}$


Table 2 Continued

\begin{tabular}{|c|c|c|c|c|c|}
\hline & \multicolumn{5}{|c|}{ Accumulated costs and impacts until } \\
\hline & 2018 & 2020 & 2030 & 2040 & 2050 \\
\hline Screening from 40 & 1260665 & 477442 & 155163 & 118834 & 107909 \\
\hline Screening from 20 & 2197194 & 852683 & 306943 & 247192 & 229604 \\
\hline \multicolumn{6}{|c|}{ Incremental cost-effectiveness ratio (deaths averted) } \\
\hline Status quo & 9867435 & 4456291 & 799119 & 395182 & 282029 \\
\hline Screening from 60 & 19277053 & 5220339 & 713661 & 476444 & 433832 \\
\hline Screening from 40 & 77654439 & 19588848 & 1673009 & 691156 & 473235 \\
\hline Screening from 20 & Dominated & Dominated & 23046095 & 7199017 & 3903209 \\
\hline
\end{tabular}

Table shows difference between scenarios in the accumulated costs and health impacts from 2017 until year indicated. We used the 2016 year-average exchange rate ${ }^{29}$ to convert Korean won to US dollars (KRW 1160) and a discount rate of $3 \%$. $^{30}$

programme contributes to successful hepatitis C control in Korea.

The results of our study indicates that scale up of screening and treatment with DAAs is cost-effective, if the comprehensive screening programme for people aged 60 or above, and that for people aged 40 or that for people aged 20 was implemented and continued by 2050 . The scale-up of screening for people aged 60 or above and that for people aged 40 or above is estimated to avert
15231 and 17374 hepatitis C infections, respectively, and avert 5310 and 5798 deaths caused by hepatitis C, respectively, for the period of 2017-2050. Furthermore, those with access to general health screening (category A) benefit more from expanded hepatitis C screening compared with those without (category B), who could be targeted by the life-turning-point health screening at the age of 40 with inclusion of hepatitis C screening. Given that Korea already has the infrastructure for ongoing

Table 3 Returns to hepatitis $C$ treatment of 100 persons in 2017 for the period 2017-2050 by sex and age

\begin{tabular}{|c|c|c|c|c|c|c|c|c|c|}
\hline & \multirow{2}{*}{$\begin{array}{l}\text { (1) Costs } \\
\\
\text { Total }\end{array}$} & \multicolumn{3}{|l|}{ (2) Savings } & \multirow{2}{*}{$\begin{array}{l}\text { Net cost } \\
\\
\text { (1) minus } \\
(2)\end{array}$} & \multicolumn{2}{|l|}{ Averted } & \multicolumn{2}{|l|}{ Cost per } \\
\hline & & $\begin{array}{l}\text { Hepatitis C } \\
\text { treatment }\end{array}$ & $\begin{array}{l}\text { Cirrhosis } \\
\text { and liver } \\
\text { cancer } \\
\text { treatment }\end{array}$ & Total & & Infection & Death & $\begin{array}{l}\text { Infection } \\
\text { averted }\end{array}$ & $\begin{array}{l}\text { Death } \\
\text { averteo }\end{array}$ \\
\hline \multicolumn{10}{|l|}{ Male } \\
\hline $20-29$ & 1039000 & 872874 & 190650 & 1063524 & -24524 & 17.0 & 1.67 & -1440 & -14680 \\
\hline $30-39$ & 1039000 & 856106 & 299994 & 1156100 & -117100 & 17.7 & 3.48 & -6609 & -33695 \\
\hline $40-49$ & 1039000 & 851311 & 501489 & 1352800 & -313800 & 15.8 & 7.82 & -19866 & -40136 \\
\hline $50-59$ & 1039000 & 836151 & 331947 & 1168098 & -129098 & 13.4 & 8.90 & -9606 & $-1450 c$ \\
\hline $60-69$ & 1039000 & 778178 & 207695 & 985874 & 53126 & 11.1 & 11.21 & 4791 & 4737 \\
\hline $70+$ & 1039000 & 606893 & 56394 & 663287 & 375713 & 8.1 & 8.09 & 46303 & 46441 \\
\hline $20+$ & 1039000 & 812871 & 311702 & 1124573 & -85573 & 13.6 & 8.14 & -6278 & $-10,512$ \\
\hline \multicolumn{10}{|l|}{ Female } \\
\hline 20-29 & 1039000 & 844363 & 18545 & 862908 & 176092 & 19.1 & 0.23 & 9216 & 764891 \\
\hline $30-39$ & 1039000 & 829795 & 39472 & 869267 & 169733 & 20.0 & 0.42 & 8492 & 399695 \\
\hline $40-49$ & 1039000 & 818503 & 95966 & 914469 & 124531 & 21.0 & 1.17 & 5944 & 106531 \\
\hline $50-59$ & 1039000 & 824358 & 156745 & 981103 & 57897 & 19.2 & 2.38 & 3022 & 24323 \\
\hline 60-69 & 1039000 & 802704 & 207761 & 1010464 & 28536 & 16.9 & 3.90 & 1685 & 7326 \\
\hline $70+$ & 1039000 & 634720 & 120913 & 755633 & 283367 & 12.0 & 3.26 & 23614 & 86936 \\
\hline $20+$ & 1039000 & 758304 & 141486 & 900666 & 138334 & 16.5 & 2.76 & 8367 & 50177 \\
\hline
\end{tabular}

Table shows costs and consequences of placing an additional 100 individuals on treatment, evaluated around the status quo scenario. Costs of testing are subsumed under treatment costs, and it is assumed that 12 individuals are tested for each person progressing to treatment. All totals are through 2050, and we used the 2016 year-average exchange rate ${ }^{29}$ to convert Korean won to US dollars (KRW 1160 ) and a discount rate of $3 \% .^{30}$ 
national health screening, adding hepatitis C screening to the life-turning-point screening could be done at relatively low cost.

The results on the cost-effectiveness of alternative strategies to a large extent reflect differences in the prevalence and disease progression by age. As the prevalence of hepatitis $\mathrm{C}$ increases with age, the yield of screening improves accordingly. The differences in the cost-effectiveness of treatment by age are more complex, reflecting factors like the state of disease which tends to be more advanced for older individuals who may have been infected a long time ago, ongoing disease progression which is faster at older ages, and underlying mortality for other causes which increases with age. Therefore, the largest benefit return on investing in hepatitis $\mathrm{C}$ treatment is among males aged $40-49$ years. A potential explanation for this is that hepatitis $\mathrm{C}$ prevalence rate in Korea for males aged $40-49$ years $(0.6 \%)$ triples compared with that for males aged $30-39$ years $(0.2 \%) .^{20}$ Further, liver disease is one of the 10 leading causes of death with the highest mortality for males in the middle-age groups in Korea. $^{23} 35$

Treating 100 additional hepatitis $\mathrm{C}$ cases in males aged between 40 and 49 at earlier stage of infection, beyond those identified under the status quo policy, generates the biggest return on investment with cumulative savings of $\$ 313800$ by 2050 . This finding is in line with the existing literature that showed that the large proportion of cirrhosis cases in Korea (approximately three-quarters of cases) were attributable to viral hepatitis ${ }^{36}$ and that the reduction of hepatitis $\mathrm{B}$ and hepatitis $\mathrm{C}$ infections contributed to reduction in cirrhosis and liver cancer. ${ }^{37}{ }^{38}$ Under a life-cycle perspective from the time of infection, we find that the status quo policy reduces mortality owing to hepatitis $\mathrm{C}$ by about three-quarters. Comprehensive screening eliminates about $20 \%$ of the remaining mortality, and results in financial savings over the life cycle of the individuals affected more than offset the higher initial costs (online supplementary appendix figure A1, appendix figure A2).

Our study has three limitations. First, due to the lack of the data that are specific to Korea population, disease progression rates and estimates of the distribution of people chronically infected by stage of disease, sex and age had to be estimated by calibrating certain parameters of the model to match available data. These parameters as well as historical incidence rates were calibrated by running the model from 1950, matching available estimates on prevalence and mortality for 2015 . Second, and related to the first, transition rates to treatment conditional on the state of disease are unavailable, our assumptions are consistent with overall treatment initiation rates but we needed to rely on assumptions on treatment initiation rates across stages of disease. Third, as discussed earlier, one of the most important aspects of the situation in Korea with regard to diagnosis of hepatitis C seemed to be the biannual general health screening. This feature has been accommodated in our model by distinguishing the population participating in the national health screening (category A) and the population who do not participate (category B). However, it is not plausible that these categories are fixed, as individuals going in for screening in 1 year may skip it in another, and vice versa. Therefore, we made an assumption that there is an annual transition rate of $5 \%$ from category A to category $\mathrm{B}$ and corresponding rates from category B to category A. The transition rate may potentially affect our results. To investigate the robustness of our findings with regard to such transitions, we conducted the sensitivity analysis with different transition rates of $0 \%$ and $10 \%$ and found that the estimates were similar with different transition rates between category A and B (online supplementary appendix table A2.2, table A2.3).

Our study provides evidence that rapid expansion of coverage of DAAs by national health insurance is cost-effective for hepatitis C control. Our study also provides new evidence on the cost-effectiveness of expanded screening and treatment for targeted populations with high prevalence of hepatitis $\mathrm{C}$, which could help its elimination in Korea, and provides a case for policy-makers to invest in rapid expansion of hepatitis $\mathrm{C}$ screening and treatment with DAAs.

Acknowledgements We thank Oh-Tak Kwon, Associate Research Fellow of HIRA, Korea for assistance with data collection.

Contributors RA conceived the original idea. JK designed the study, collected the data, analysed and interpreted the data and wrote the manuscript with input from all authors. MH constructed the model, analysed and interpreted the data. RA and SK supervised the project and contributed to the interpretation of the results. All authors provided critical feedback and contributed to the final version of the manuscript.

Funding This work was supported by Harvard Medical School Center for Global Health Delivery-Dubai.

Competing interests None declared.

Patient consent for publication Not required.

Provenance and peer review Not commissioned; externally peer reviewed.

Data availability statement Data are available in a public, open-access repository.

Open access This is an open access article distributed in accordance with the Creative Commons Attribution Non Commercial (CC BY-NC 4.0) license, which permits others to distribute, remix, adapt, build upon this work non-commercially, and license their derivative works on different terms, provided the original work is properly cited, appropriate credit is given, any changes made indicated, and the use is non-commercial. See: http://creativecommons.org/licenses/by-nc/4.0/.

\section{REFERENCES}

1. World Health Organization. Global health sectors strategy on viral hepatitis 2016-2021, 2016.

2. World Health Organization. Global report on access to hepatitis $C$ treatment focus on overcoming barriers, 2016.

3. World Health Organization. The selection and use of essential medicines report of the WHO expert Committee, 2015 (including the 19th WHO Model List of essential medicines and the 5th WHO Model List of essential medicines for children, 2015.

4. Hacker M. Egypt's Viral Hepatitis Program - Burden and Response: An Economic Analysis. Washington DC: World Bank's Technical Assistance on Strengthening Egypt's Response to Viral Hepatitis, 2017.

5. Hecht R, Hiebert L, Spearman WC, et al. The investment case for hepatitis B and $C$ in South Africa: Adaptation and innovation in 
policy analysis for disease program scale-up. Health Policy Plan 2018;33:528-38.

6. Hagan LM, Yang Z, Ehteshami M, et al. All-oral, interferon-free treatment for chronic hepatitis C: cost-effectiveness analyses. J Viral Hepat 2013;20:847-57.

7. Andrieux-Meyer I, Cohn J, de Araújo ESA, et al. Disparity in market prices for hepatitis $\mathrm{C}$ virus direct-acting drugs. Lancet Glob Health 2015;3:e676-7.

8. Iyengar S, Tay-Teo K, Vogler S, et al. Prices, costs, and affordability of new medicines for hepatitis $\mathrm{C}$ in 30 countries: an economic analysis. PLoS Med 2016;13:e1002032.

9. Barua S, Greenwald R, Grebely J, et al. Restrictions for Medicaid reimbursement of sofosbuvir for the treatment of hepatitis $\mathrm{C}$ virus infection in the United States. Ann Intern Med 2015;163:215-23.

10. Rosenthal ES, Graham CS. Price and affordability of direct-acting antiviral regimens for hepatitis $\mathrm{C}$ virus in the United States. Infect Agent Cancer 2016;11.

11. Ministry of Health and Welfare. Insurance to cover costs for Solvadi and Harvoni beginnig may 1st, 2016. Ministry of Health and Welfare, 2016.

12. Jeong S-H, Jang ES, Choi HY, et al. Current status of hepatitis C virus infection and countermeasures in South Korea. Epidemiol Health 2017;39:e2017017.

13. Kim BK, Jang ES, Kim JH, et al. Current status of and strategies for hepatitis $\mathrm{C}$ control in South Korea. Clin Mol Hepatol 2017;23:212-8.

14. Korean Association for the Study of the Liver. Korean association for the study of the liver. Liverday_2016, 2016. Available: http://www. kasl.org/bbs/index.html?code=report\&category=\&gubun=\&page $=$ $1 \&$ number $=3016 \&$ mode $=$ view\&keyfield $=\& k e y=[$ Accessed $04 \mathrm{Mar}$ 2019].

15. National Health Insurance Service. National health screening statistical Yearbook. 2015, 2015.

16. Maasoumy B, Wedemeyer $\mathrm{H}$. Natural history of acute and chronic hepatitis C. Best Pract Res Clin Gastroenterol 2012;26:401-12.

17. Poynard T, Bedossa P, Opolon P. Natural history of liver fibrosis progression in patients with chronic hepatitis C. The Lancet 1997;349:825-32.

18. United Nations. World population prospects 2017, 2017. Available: https://esa.un.org/unpd/wpp/DataSources/ [Accessed $06 \mathrm{Apr}$ 2019].

19. Institute for Health Metrics and Evaluatoin (IHME). Global burden of Disease Study 2015 (GBD 2015), 2016. Available: http://ghdx. healthdata.org/gbd-results-tool [Accessed 06 Apr 2019].

20. Korea Centers for Disease Control and Prevention. Korea National Health and Nutrition Examination Survey (KNHANES), 2015.
21. Korean Organ Transplantation Registry. KOTRY annual report 2015 2015.

22. National Evidence-based Healthcare Collaborating Agency. The impact of the National Liver cancer surveillance program on the early detection, mortality and medical cost, 2016.

23. Statistics Korea. Causes of death statistics of 2015, 2016.

24. Koean Network for Organ Sharing (KONOS). Organ transplant statistics, 2016

25. Health Insurance Review \& Assessement Service. Healthcare Bigdata Hub Health Insurance Review \& Assessement Service, 2017. Available: http://opendata.hira.or.kr/op/opc/olapMfrnlntrslln slnfo.do

26. Health Insurane Review \& Assessement Service. Hepatitis C. In: Kwon O-tak, ed. HIRA, 2017.

27. Razavi $\mathrm{H}$, Waked I, Sarrazin $\mathrm{C}$, et al. The present and future disease burden of hepatitis $\mathrm{C}$ virus ( $\mathrm{HCV}$ ) infection with today's treatment paradigm. Journal of Viral Hepatitis 2014;21:34-59.

28. World Health Organization. Guidelines for the screening, care and treatment of persons with hepatitis $C$ infection. Guidelines for the screening, care and treatment of persons with hepatitis $C$ infection. Geneva, 2014.

29. OECD. Exchange rates, 2016. Available: https://data.oecd.org/ conversion/exchange-rates.htm

30. Basu A, Ganiats TG. Discounting in cost-effectiveness analysis. Cost-Effectiveness in Health and Medicine 2016;277.

31. Health Insurance Review \& Assessement Service. Medication Prices: Health Insurance Review \& Assessement Service, 20prices: health insurance review \& assessement se16.

32. Kim H-L, Park J-A, Sin J, et al. Analysis of medical use and costs Relatd to the management of liver cirrhosis using national patients sample data. Korean Journal of Clinical Pharmacy 2016;26.

33. Asan Medical Center. Liver transplant, 2017. Available: http:// organ.amc.seoul.kr/asan/depts/organ/K/content.do?menuld=1610 [Accessed 2017/09/20].

34. Jeong S-H. Epidemiology of hepatitis $\mathrm{C}$ virus infection in Korea. Korean Journal of Medicine 2015;88:630-4.

35. Shin H-Y, Lee J-Y, Song J, et al. Cause-of-death statistics in the Republic of Korea, 2014. J Korean Med Assoc 2016;59:221-32.

36. Lee SS, Byoun Y-S, Jeong S-H, et al. Type and cause of liver disease in Korea: single-center experience, 2005-2010. Clinical and Molecular Hepatology 2012;18:309-15.

37. Lim D, Ha M, Song I. Trends in the leading causes of death in Korea, 1983-2012. J Korean Med Sci 2014;29:1597-603.

38. Perz JF, Armstrong GL, Farrington LA, et al. The contributions of hepatitis $B$ virus and hepatitis $C$ virus infections to cirrhosis and primary liver cancer worldwide. J Hepatol 2006;45:529-38.

39. World Health Organization. Global hepatitis report, 2017, 2017. 